\title{
Using Experiential Client-Based Projects in Sport Sales Courses
}

David Pierce, Indiana University-Purdue University Indianapolis, Indianapolis, USA

\begin{abstract}
Sales has gradually gained traction in the sport management programs over the past 15 years. This article examines the extent to which client-based experiential projects are used in sport sales courses and determines if teaching practices are different in client-based and non-client-based courses. Online survey responses were received from 36 of 85 sport management programs that offer a sport sales course. Results indicated that $58.3 \%$ of sport sales courses utilized a client-based experiential sales project. The sports properties that partner with sales classes the most are college athletics, minor league teams, and Big Five professional sports teams. Clients provided students with leads in $55 \%$ of the projects. The most popular organizational model was the independent model, which was employed by $70 \%$ of the courses engaging in a clientbased project, followed by the on-campus and in-venues models. Client-based courses were more likely to use mock sales calls, guest speakers, and the Sales Huddle game. Implications for teaching client-based experiential courses are addressed.
\end{abstract}

\section{KEYWORDS}

Experiential learning, Sales education, Sport management education, Sport management, Sport sales 


\section{INTRODUCTION}

\section{Using Experiential Client-Based Projects in Sport Sales Courses}

Despite the fact that sales is a career pursued by many majors on college campuses, a shortage of sales talent exists in many fields, including sport management (Cummins, Peltier, Erffmeyer, \& Whalen, 2013; Popp, Simmons, McEvoy, 2017). Within the sport industry, the growth of business-to-consumer inside sales teams in professional sports and college athletics has created demand for qualified salespeople (Pierce, Popp, \& McEvoy, 2017). Sales positions outnumber all other types of entry-level positions by a 3-to-1 margin, according to data available on leading sports job search site Teamwork Online. For example, ticket sales and service positions accounted for $34 \%$ of all entry-level jobs on Teamwork Online in October 2017, and this number rises to $41 \%$ when including jobs in sponsorship sales. In sum, ticket and sponsorship sales positions accounted for $24 \%$ of all jobs on the site. Another leading website for job searches, Work In Sports, estimated that $53 \%$ of job postings require some level of sales experience or competence (Clapp, 2016). Despite the prevalence of entrylevel jobs in sales, sport management programs have been slow to respond to this marketplace reality. A comprehensive review of sport management programs revealed that only $22 \%$ of undergraduate sport management programs have a course in sport sales (Pierce, in press). This adoption rate mirrors the $21 \%$ adoption of sales courses in AACSB-accredited institutions in business schools (Fogel, Hoffmeister, Rocco, \& Strunk, 2012). The underrepresentation of sales education in the sport management curriculum is problematic given the significant quantity of entry-level positions and the above-average compensation levels and upward mobility for those successful in those entry-level positions (Pierce et al., 2017).

The paucity of sales education within the sport management curriculum has resulted in a void of sales talent prepared to fill the available positions. Compounding the problem on the academic side of the equation are the ineffective sales management strategies used to prepare entry-level salespeople for success. Kirby (2017) noted the high turnover rate stems from forcing entry-level salespeople in their early 20 s, who rarely use their smartphone for phone calls, to make 100 scripted calls per day in a boiler room environment. This creates a top-down indoctrination structure that does not allow for creative thinking and offers little professional development and training. In fact, Popp et al. (2017) found nearly a quarter of sales hires in college athletics received fewer than two hours of training before making their first sales call. Even more shocking, half of the respondents to the survey indicated that their employer provided fewer than two hours of monthly on-going training. As a result, entry-level sport sales positions have seen high rates of turnover. It is estimated that five out of six entry-level ticket salespeople either choose to leave sales or are let go from their positions (King, 2010), a rate significantly higher than the $28 \%$ annual turnover in other businesses (Fogel et al., 2012). Therefore, it is critical that sport sales educators provide students with high-quality sales education that simulates real-world environments to best prepare them to succeed in their first sales position. 
Sales educators are increasingly focused on linking theory to practice through experiential learning (Irwin, Southall, \& Sutton, 2007; Pierce \& Petersen, 2015). Because the most basic purpose of sales education is to provide students with the competencies needed for success in sales, sales education should utilize an experiential approach where faculty serve as the coach (Anderson et al., 2005). Students can get experience making actual sales calls through client-based experiential sales projects. Professional sales courses in the business education literature have presented similar projects with students selling advertising for newspapers or magazines and attracting students to the business major (Chapman \& Avila, 1991; Milner, 1995). These projects move beyond role-playing and video analysis, which stop short of giving students a complete sales experience, by offering students the opportunity to make sales calls. Reliance on lecture, role-playing, and video analysis does not provide students with a complete selling experience because students miss prospecting, talking to customers, conducting a needs analysis, and following up to close the sale.

The extent to which client-based projects are utilized is currently unknown in the business and sport management literature. It is also unknown how teaching methods differ for those using client-based projects and those not using client-based projects. The purpose of this study is to examine the extent to which client-based experiential projects are used in sport sales courses in the United States and determine if teaching practices differ between client-based courses and non-client-based courses. To accomplish this purpose, individuals leading sport management programs with sport sales courses completed an online survey regarding the pedagogical strategies employed to teach sport sales courses. Specifically, the survey focused on the teaching methods that undergird client-based sales projects. This research is the first attempt to examine trends in sport sales pedagogy. It provides instructors and decision-makers with guidelines for the successful implementation of client-based sales courses, which can provide students a stepping-stone to a career with ample entry-level employment opportunities, upward mobility, and above-average compensation levels (Pierce et al., 2017). This study heeds the recommendation of Cummins et al. (2013) to report on successful pedagogy in the area of experiential learning.

\section{LITERATURE REVIEW}

Experiential learning projects that simulate real-world sales situations have received attention from sales scholars in sales and marketing education journals in recent years. Cummins et al. (2013) found that experiential learning articles account for the largest percentage of research articles in the area of sales education. Experiential learning can take many forms in sales education, including case studies, simulations, role-play, videotaping, salesperson observation, improvisation, competitions, and client-based projects. However, only client-based experiential projects are authentic because they simulate a real-world sales environment where students engage with real customers to sell real products and services (Chapman \& Avila, 1991; Rippe, 2015). Cummins et al. (2013) noted the need for integration of sales projects and classroom-based 
selling experiences when sales courses are being designed. Chapman and Avila (1991) were the first to develop guidelines for faculty implementing an experiential project within a professional selling course. They discussed how faculty can provide students with sales experience through selling advertising for sports teams, memberships for a blood bank and Better Business Bureau, and novelty items for a manufacturer. Milner (1995) explained how students could gain experience through a telemarketing project attracting potential undergraduate students to their own business school. More recently, Rippe (2015) presented the "show and sell" concept where students sold chocolate bars to businesses and consumers. Bussiere (2017) discussed how an experiential sales project was designed to sell advertising space in a one-time newspaper insert.

Within the sport management literature on sales education, three key frameworks have undergirded the development of client-based experiential sport sales courses. The seminal paper to set the path for sport sales courses is the Pentagon of Sport Sales Training Model (PSSTM) (Irwin et al., 2007). The PSSTM advocated for the integration of client-based experiential sales projects to be included in sport sales courses. In these courses, students make sales calls for sports properties in an authentic experiential environment. The PSSTM established how sport sales training programs can partner with clients to create an experiential learning environment conducive to students making successful sales calls. It emphasized five modules: the importance of exposing students to and embedding them in the client's sales philosophy and culture (philosophy); rigorous training and testing on the client's product to ensure students have a competent level of product knowledge (product); providing students with prospects that have a previous relationship with the client to avoid cold-calling (prospect); having students practice their skills through script development and rehearsal, role-playing, video and audio analysis, and mock sales calls (practice); and executing the sales call in an authentic, real-world environment where performance is assessed (performance).

Pierce and Petersen (2015) built on the PSSTM and detailed five steps needed to execute a successful client-based experiential sales project. In the project initiation phase, faculty secure the client and any internal support needed such as computer or classroom space. Next, the type of sales project is selected. The nature and distribution of leads is a key decision at this point in the planning. Essentially, at this stage it is determined who the students will be calling and how leads will be obtained. Options are on a continuum from students doing their own prospecting with no leads to being given leads directly from the client's database. The other decision at this point is what the students will be selling. Options are on a continuum from single game events to full-menu marketing, where students can sell all of the organization's inventory like season tickets, groups, and corporate hospitality. Third, Pierce and Petersen outline sales training methods and the use of site visits, training manuals, role-playing, mock sales calls, sales games, and product knowledge. Fourth, they discuss three models for executing projects. In the remote call center model, a sales center is established on campus for students to conduct sales calls in a call center environment. The on-site call center utilizes the technology and resources of the client, and students make sales 
calls from the front office of the client. The independent project requires students to make sales calls on their own time with no structured environment in the class. At this stage of executing the project, it is also important for client and faculty to work together to build a positive sales culture in the class to keep students positive and motivated throughout the experience. Finally, the authors presented a sales competency dashboard that could be used to monitor and assess student performance and learning outcomes in the project.

While the PSSTM and the paper by Pierce and Petersen provided a robust framework for executing client-based experiential sales projects, a void existed in what competencies students needed to demonstrate to be successful. While revenue generation is the easiest metric to use, it may not tell the most complete story of student growth, learning, and performance (Pierce \& Irwin, 2016). As a result, Pierce and Irwin (2016) developed the sport sales competency model using the Delphi method with feedback from sport sales managers. The model presented holistic rubrics to define levels of performance for nine competencies: communication skills, opening, knowledge and skill development, relationship building, needs analysis, overcoming objections, presenting solutions, closing, and maximizing the sale. This competency model with clearly articulated levels of performance adds depth and substance to the practice module of the PSSTM and the training stage of Pierce and Petersen's (2015) model while also providing an evaluative framework to assess student performance.

Measures of direct learning and other attitudinal outcomes in client-based sport sales courses have also been examined. Pierce and Petersen (2010) confirmed the hypothesis of Chapman and Avila (1991), who hypothesized that giving students actual sales experience will help them make better career choices resulting from a more informed expectation about what a sales career is like. "It may also help weed out students who had unrealistic expectations of a sales career, thus, reducing employee turnover by improving students' attitudes and job preparation" (Chapman \& Avila, 1991, p. 58). Pierce and Petersen (2010) found that students significantly decreased their expectation for a career in sport sales after the completion of a client-based sales course. They concluded that completing an experiential sales project served as a realistic job preview that lowered initial job expectations and likely increased the number of students who would not pursue sales as a career. Wanless, Brewer, Johnson, and Judge (2016) also found that offering an experiential sales project provides students with a realistic career preview. Pierce, Petersen, and Meadows (2011) conducted an authentic assessment of student sales calls in a control and experimental group and found that students in a sport sales class improved their ability to open the sales call and exude enthusiasm compared to the control group, but there was no difference in the students' ability to ask probing questions or demonstrate confidence.

While there is research on the design and outcomes of client-based experiential courses in the sales literature, the extent to which client-based experiential projects are utilized is unknown in both business and sport management sales education. Unfortunately, the most recent review of sales education in business schools conducted by Deeter-Schmelz and Kennedy in 2011 did not include client-based experiential 
learning as one of the eleven teaching methods examined in the study. Thus, it is not known how widely client-based projects are being adopted, nor how sales courses are being taught. As a result, the following research questions were developed:

- To what extent and in what form are client-based experiential projects used in sport sales courses?

- Are teaching practices different for client-based courses than non-client-based courses?

Given the challenges facing entry-level salespeople in the sport industry, it is important for sport management programs to make curricular decisions based on established best practices. The results of this study provide an overview of current teaching practices in sport sales courses. The advantages and disadvantages of these approaches are discussed in light of best practices.

\section{Methods}

Undergraduate sport management programs in the United States were identified using the listing provided on the website degreesinsports.com, which is recognized as the most credible repository for information on sport management programs based on its endorsement from the North American Society for Sport Management. University websites were used to examine the program's curriculum to determine if the program offered a sport sales course. Courses that included the terms sales, selling, or revenue generation somewhere in the title were counted as offering sales, in addition to courses that identified the sales process in the course description. Eighty-five sport sales courses were identified. Two coders independently coded the courses and agreed on all 85 courses.

\section{Participants}

University Internet sites were used to obtain individual e-mail addresses for the population of 85 programs offering a sport sales course. The primary target was the undergraduate sport management program director. If the website did not list a sport management program director, an e-mail was sent to the department chair. Department chairs and program coordinators were encouraged to forward the survey link to the sport sales instructor, if appropriate. Responses were collected via an online survey system. Potential respondents were sent an e-mail requesting voluntary participation in the study. A link to the survey was included in the e-mail. A follow-up e-mail was sent the following week. Thirty-six of the 85 programs with sales responded for a $42.4 \%$ response rate. The majority of the respondents were sales course instructors $(55.6 \%)$, followed by sport management program directors $(50 \%)$, and department chairs $(8.3 \%)$. These numbers exceed $100 \%$ because an individual could hold more than one title. 
Table 1. Client-based experiential survey questions

\begin{tabular}{|l|}
\hline Does the client provide the students with leads to call on? (select one) \\
\hline Yes (students are given leads from the team's CRM or database) \\
\hline No (students prospect their own leads) \\
\hline Both (it depends on which project or semester)
\end{tabular}

Not sure

Research has shown there are three primary ways to implement a sales project for a client. Which of these models is used by your sales class? (select all that apply)

On-campus sales center (your department has dedicated space on campus for students to make sales calls supervised by the instructor)

In-venue sales center (students travel to the sport organization home offices to make calls supervised by the instructor and the team's sales staff)

Independent (students primarily make sales calls through contacting people in their own personal network on their own time not supervised directly by the instructor)

Table 2. Client-Based Experiential Learning

\begin{tabular}{|c|c|c|}
\hline Survey Item & $\mathbf{N}$ & Pet. \\
\hline \multicolumn{3}{|l|}{ Lead Distribution $(\mathrm{n}=21)$} \\
\hline Students do own prospecting & 9 & $42.9 \%$ \\
\hline Receive leads from CRM & 4 & $19.0 \%$ \\
\hline Students received leads and do their own prospecting & 7 & $33.3 \%$ \\
\hline Not sure & 1 & $4.8 \%$ \\
\hline \multicolumn{3}{|l|}{ Sales Project Execution $(n=20)$} \\
\hline Independent & 14 & $70 \%$ \\
\hline On-campus sales center & 7 & $35 \%$ \\
\hline In-venue sales center & 6 & $30 \%$ \\
\hline \multicolumn{3}{|l|}{ Partnering Organizations $(\mathrm{n}=21)$} \\
\hline Athletic department at home institution & 11 & $52.4 \%$ \\
\hline Minor league team & 11 & $52.4 \%$ \\
\hline Big Five professional sports team & 10 & $47.6 \%$ \\
\hline Athletic department at another institution & 6 & $28.6 \%$ \\
\hline Non-profit organization & 6 & $28.6 \%$ \\
\hline Spectator event (i.e., golf, auto racing) & 4 & $19.0 \%$ \\
\hline Campus group or organization & 4 & $19.0 \%$ \\
\hline Sport marketing agency & 2 & $9.5 \%$ \\
\hline Participant event (i.e., road races, marathon) & 2 & $9.5 \%$ \\
\hline
\end{tabular}




\section{Nonresponse Bias}

Nonresponse bias was assessed by ensuring there were no differences between the 36 institutions that completed the survey and the 49 institutions that did not complete the survey.

Characteristics about the institution were collected from the Carnegie Classification of Institutions of Higher Education website (carnegieclassifications.iu.edu). Variables examined included size of the university (large, medium, small), residential nature of the campus (highly residential, primarily residential, non-residential), Carnegie classification (doctoral, masters, baccalaureate), selectivity (most selective, selective, inclusive), whether the school is public or private, and type of geographic location (city, suburb, town). A chi-square test was conducted for each variable, and no significant difference was found between institutions that completed the survey and those that did not complete the survey.

\section{Measures}

The first question confirmed the sport management program offered a course predominantly devoted to teaching students how to sell within the sport industry (i.e., prospecting, opening, needs analysis, presenting solutions, overcoming objections, closing, upselling, referrals, service after the sale). The next question determined whether the course used client-based experiential learning by asking whether the class partners with a client to students' experience selling. If the respondent answered yes to this question, they received questions about the types of organizations serving as the client, how the student obtained leads, and how the sales project was executed. The definitions provided by Pierce and Petersen (2015) were used to create these questions.

Finally, all respondents were asked what sales training and assessment methods are used in the course. This list was built from the work of Deeter-Schmelz and Kennedy (2011) and added the use of the Sales Huddle game and mock sales calls to the list of teaching methods. The Sales Huddle game, now called 1-Huddle (www.1huddle. co), was launched in 2013 as a sales training tool for sports properties. Sport sales instructors have also adopted it as a way to engage students in a gamified environment. Students compete against each other on a sales leaderboard by answering questions on a mobile device, and then compete in-person against other students using a jeopardystyle game that focuses heavily on the use of role-play. Instructors that use the Sales Huddle game would, by definition, also use role-play as the Sales Huddle game uses role-playing. Mock sales calls were added to the survey based upon Irwin et al.'s (2007) differentiation between role-play and mock sales calls. They note that role-playing pairs students together as seller and customer to practice various stages of the sales process, but "rarely simulates the dynamic caller-receiver interaction encountered in a real-world sales environment" (p. 34). Therefore, an additional mode of practice called the mock sales call is required, where students engage in a mock sales conversation with a member of the sport property's sales staff.

Demographic information about the program was also collected, including questions about the number of students in the major, typical class size, distance from 
Table 3. Comparison of Sales Training and Assessment Methods

\begin{tabular}{|c|c|c|c|c|c|c|c|c|c|c|}
\hline \multirow[t]{2}{*}{ Method } & \multicolumn{2}{|c|}{$\begin{array}{l}\text { Client- } \\
\text { Based } \\
(\mathrm{N}=18)\end{array}$} & \multicolumn{2}{|c|}{$\begin{array}{c}\text { Not Client- } \\
\text { Based } \\
(\mathbf{N}=15)\end{array}$} & \multicolumn{2}{|c|}{$\begin{array}{c}\text { Study } \\
\text { Total } \\
(\mathbf{N}=33)\end{array}$} & \multicolumn{2}{|c|}{$\chi^{2}$ Results } & \multicolumn{2}{|c|}{$\begin{array}{c}\text { Deeter-Schmelz, } \\
\text { \& Kennedy } \\
(\mathbf{2 0 1 1}) \\
(\mathbf{N}=\mathbf{9 2})\end{array}$} \\
\hline & $\mathbf{n}$ & Pct. & $\mathbf{n}$ & Pct. & $\mathbf{n}$ & Pet. & $\chi^{2}$ & $p$ & $\mathbf{n}$ & Pet. \\
\hline Lecture & 18 & $100 \%$ & 14 & $93.3 \%$ & 32 & $97.0 \%$ & 1.2 & .455 & 84 & $91.3 \%$ \\
\hline Guest speakers & 18 & $100 \%$ & 11 & $73.3 \%$ & 29 & $87.9 \%$ & 5.5 & .033 & 78 & $84.8 \%$ \\
\hline Role-Playing & 15 & $83.3 \%$ & 13 & $86.6 \%$ & 28 & $84.8 \%$ & 0.1 & .591 & 87 & $94.6 \%$ \\
\hline Sales presentations & 16 & $88.8 \%$ & 11 & $73.3 \%$ & 27 & $81.8 \%$ & 1.3 & .242 & 65 & $70.7 \%$ \\
\hline Mock sales calls & 15 & $83.3 \%$ & 6 & $40 \%$ & 21 & $63.6 \%$ & 6.6 & .013 & -- & -- \\
\hline Written sales proposals & 10 & $55.5 \%$ & 10 & $66.6 \%$ & 20 & $60.6 \%$ & 0.4 & .386 & 34 & $37.0 \%$ \\
\hline $\begin{array}{l}\text { Student learning outcomes } \\
\text { reports }\end{array}$ & 9 & $50.0 \%$ & 6 & $40.0 \%$ & 15 & $45.4 \%$ & 0.3 & .565 & -- & -- \\
\hline $\begin{array}{l}\text { Video recorded sales } \\
\text { presentations }\end{array}$ & 8 & $44.4 \%$ & 5 & $33.3 \%$ & 13 & $39.4 \%$ & 0.4 & .386 & 60 & $65.2 \%$ \\
\hline Watching videos & 9 & $50 \%$ & 3 & $20 \%$ & 12 & $36.4 \%$ & 3.2 & .077 & 51 & $55.4 \%$ \\
\hline Sales Huddle game & 7 & $38.8 \%$ & 0 & $0 \%$ & 7 & $21.2 \%$ & 7.4 & .007 & -- & - \\
\hline Computer simulation & 2 & $11.1 \%$ & 2 & $13.3 \%$ & 4 & $12.1 \%$ & 0.1 & .626 & 6 & $6.5 \%$ \\
\hline
\end{tabular}

the closest Big Five (Major League Baseball, National Football League, Major League Soccer, National Basketball Association, and National Hockey League) professional sports team, and whether data from the class is used in student learning outcomes assessment reporting.

\section{Data Analysis}

Chi-square tests were employed to examine the relationship between teaching methods used in the class and whether or not the sales class collaborated with a client. T-tests were used to compare the difference between client-based and non-client-based course based on size of the major, typical class size, and distance from a Big Five professional sports team.

\section{Results}

Twenty-one of 36 sales courses (58.3\%) utilized a client-based experiential sales project as a key component to the sales course. The three most common types of sports properties that partner with sales classes are college athletic departments (52.4\%), minor league teams (52.4\%), and Big Five professional sports teams (47.6\%). Students were not given any leads by the client and did their own prospecting in 9 of the 21 programs that used client-based projects. Students sold exclusively from the customer relationship management (CRM) in four programs, and students could do a mix of calling from CRM leads and their own prospecting in seven of the programs. In sum, clients provided students with leads in $52 \%$ of the programs. The most popular organizational model for the sales project was the independent model, which was 
employed by $70 \%$ of the programs engaging in a client-based project. The on-campus model was used by $35 \%$ of the programs, while the in-venue model was used by $30 \%$. A summary of results is found in Table 2.

Eighteen of 21 respondents with client-based sales courses answered questions about teaching and assessment methods in the course. Lecture, guest speakers, roleplaying, and presentations were used by over $80 \%$ of the client-based courses, and mock sales calls and written sales proposals were used by nearly $66 \%$ of client-based courses. The use of technology through video recorded sales presentations, the Sales Huddle game, and computer simulations were used with much less frequency. Three methods were more likely to be used by courses using a client-based sales project, as measured by significant chi-square results. Client-based courses were more likely than non-client-based courses to use mock sales calls, guest speakers, and the Sales Huddle game. A summary of results is found in Table 3.

No significant differences existed between the use of client-based experiential project usage or size of the major or typical class size. However, there was a significant difference in miles from the nearest Big Five professional sports team. Programs adopting a client-based experiential learning project resided closer to a city with a Big Five professional sports team $(M=51.1 \mathrm{miles}, S D=10.3)$ than programs not utilizing this pedagogical method $(M=86.1$ miles, $S D=20.4), t(34)=1.67, p<.01$.

\section{DISCUSSION}

Courses devoted to sales have gradually gained traction within the curriculum of sport management programs over the past 15 years (Pierce, in press), and those courses have embraced the applied nature of sales as evidenced by the predominant use of client-based experiential sales projects. Results of this study showed that nearly $60 \%$ of sport sales courses place the student in the role of salesperson on behalf of a client. It appears that the Pentagon of Sport Sales Training Model (Irwin et al., 2007) and the framework described by Pierce and Petersen (2015) have established a usable pedagogical framework for instructors choosing to use a client-based experiential sales project in a sport sales class.

In comparing differences between programs that used client-based experiential sales projects and those who do not, the results showed that program and class size did not affect the adoption of client-based courses. This may mean that up to a certain class size, client-based sales projects are a scalable experiential project. Once the infrastructure for the sales projects is established, the addition of additional students may not prove burdensome, at least to a certain point. Instructors have the luxury of adding more students to the course provided they have access to enough space to house all students making sales calls, receive support in the form of project managers from the client, and can tap into a pool of student peer mentors who have successfully completed the sales class in a past semester.

While class and program size was not significant, distance from a Big Five professional sports team was significant. Programs adopting a client-based experiential 
project resided 35 miles closer on average to a city with a Big Five professional sports team than programs not utilizing this pedagogical method. Programs located at an institution where the athletic department lacks a saleable product, or programs distant from a professional sports team, face challenges to the successful implementation of a client-based sales projects. However, the results of this study show that there are other partners available to give students sales experience. Non-profit organizations, spectator sporting events, campus groups, and participant-based events can all provide students with an authentic experience in sales. For example, a sport management program at an NCAA Division III institution located 200 miles away from the closest Big Five professional sports team may want to partner with a running or cycling race, triathlon, warrior dash, or some other type of participant-based event. Looking to the literature on professional selling in business school courses, students could also partner with the athletic department to sell corporate sponsorship and advertising instead of ticket packages to games. For example, McKelvey and Southall (2008) discussed how students partnered with a local collegiate baseball team to sell sponsorship.

\section{Prospecting and Lead Distribution}

Courses with a client-based experiential project have found willing partners within their own athletic department, Big Five professional sports teams, and minor league teams. In developing these projects with clients, the first decision that has to be made is whether or not the client is going to provide students with leads from the organization's CRM system. Programs were essentially split on their use of leads from the sport property's CRM. Excluding the one respondent who was not sure which model was used in the program, clients provided leads in $55 \%$ of the programs and did not provide leads in $45 \%$ of the programs. It is important to realize that the decision on whether or not the organization provides leads is not mutually exclusive. It is possible to have students do their own prospecting and receive CRM leads during the same project. The most robust and real-life experience for students is to have them make calls to people they do not know from the CRM, but also leverage their own personal network to build a broader base of prospects. To ensure the best experience for the student, faculty should:

1. Ensure students receive warm leads from the client's CRM system. Having students make cold calls to customers on a purchased list is not advisable due to the high rate of rejection that students will experience. Instead, students should be contacting prospects who have recently engaged with the client's product or service. An ideal scenario is that the team has used another direct marketing tactic to communicate with the prospect in the weeks leading up to the students making sales calls.

2. Create clear lines of communication with the client regarding business-to-business (B2B) prospects that should not be contacted. Relationships can be damaged when students try to sell a small group outing to a business prospect that is already a season ticket holder or corporate partner. If students are doing their own B2B prospecting, they need clear guidelines on who is permissible to contact. 
3. Utilize a real-time collaborative platform like Google Drive to manage the thousands of contacts students are making. Faculty need to have all of the contacts and call results accessible in one easy-to-find location.

\section{Independent Project Model}

The most common model for executing client-based sales projects is the independent project model where there "is no structured call center environment and students make the sales calls on their own time and use their own technology" (Pierce \& Petersen, 2015, p. 69). By and large, students call on their own network of leads with these projects, although six programs reported using this model with students also obtaining CRM leads from the client. The independent project model is attractive because the organizational burden on the instructor is minimal and students can work around their personal schedule to make sales calls, but there are important disadvantages to consider. Perhaps the biggest drawback to the independent project model is the concern that low-income students are at a disadvantage because they do not have a personal network that can afford to buy tickets. Students that are more affluent can more easily access people with buying capacity in their personal network (Mueller, 2014).

In addition to equity concerns, the effort exerted by the sport organization to create a positive experience for the students can also be problematic. Sheptak and Menaker (2016) found that students felt isolated from the organization if the sales manager demonstrated low levels of engagement with the students. Slow response times from the sales manager to student questions resulted in high levels of frustration. This left students feeling that the organization did not care about their success. Students felt as if they were being used by the organization with no thought for the educational value of the experience or professional development of the student. This feeling was compounded by the fact that students did not feel that the course content prepared them to be successful selling the team's tickets and packages. It is recommended instructors do the following to alleviate these problems in the independent sales project:

1. Deliver sales training prior to the start of the sales project to ensure that students can demonstrate sales competencies. Ensure a tight link between course content and competencies that students will need to demonstrate. This study found that mock sales calls and the Sales Huddle game were more likely to be used by instructors preparing their students for a client-based experiential project. Both of these methods provide students with the prerequisite knowledge checks and experience to be successful in a sales project environment.

2. Develop a communication platform that facilitates timely communication between students, faculty, and the organization. For example, the organization should answer student e-mails within 48 hours, and completed sales should be updated on the class sales board within 24 hours. The use of technology to complete the sale, like a Web link customized to each individual student, facilitates faster closing times than paper forms and collecting cash and checks. 
3. Provide opportunities during the semester for face-to-face or online guest lectures from the project manager or other sales representatives with the sport organization. Engagement between the team and students should occur more than once at the beginning of the project.

4. Create small incentives that create a positive sales culture throughout the project. Adding weekly goals keeps all students engaged throughout the course of the project.

5. Provide adequate training on prospecting for leads outside of your own personal network and leveraging social media to help lower-income students identify leads with the capacity to purchase tickets.

Following these five guidelines will significantly enhance the student experience on an independent sales project where students do their own prospecting.

\section{Calling Warm Leads From the CRM}

The most authentic or "real-life" approach to client-based sales projects is to have students work in a call center environment making warm calls from the CRM. This model was used at approximately the same rate as the independent model. Sixty-five percent of programs responding to the survey said they use either the in-venue or campus-based sales center model. It is important to note that programs can utilize both of the models if different types of projects are used in different semesters. The in-venue or on-campus sales center experience replicates the job of an entry-level inside sales position in college and professional sports. The advantage to this model is its authenticity, connection to the organization's sales culture, and opportunity for assessment. Instructors and salespeople with the partnering organization directly assess each student's competence in key areas like opening the call, conducting a needs analysis, presenting solutions, overcoming objections, closing, and upselling (Pierce \& Irwin, 2016). Program directors with client-based experiential projects should consider adding sales to the program's assessment plan, particularly in light of the fact that only half of experiential-based sales courses were included in the program's assessment plan. The disadvantage to the call center model is it does require more organization by the faculty member and typically places additional time requirements beyond the normally scheduled class time for students. In addition to the recommendations already provided above, faculty should do the following in call center-based projects to provide students with the best experience:

1. Recruit students from past projects to serve as project coordinators to assist with call center logistics and communication between students and client.

2. Adopt the competency framework from Pierce and Irwin (2016) to assess student sales calls performed in the sales center.

3. Ensure students have access to the technological tools to be successful in the sales center. Wi-Fi should be reliable and fast. Students also need to know how to utilize applications like Google Voice to make free calls using their smartphone, secure 
a phone number that matches the market in which they are selling, and make calls from their smartphone, tablet, or laptop.

4. Utilize just-in-time teaching methods to provide the class with short bursts of training and feedback that they can immediately incorporate into their calls.

\section{Teaching Methods}

As noted earlier, a direct comparison cannot be made between the use of client-based sales projects in sport and business contexts, as the Deeter-Schmelz and Kennedy (2011) paper did not include client-based projects as one of the 11 teaching methods under investigation. The addition of mock sales calls and the Sales Huddle game proved relevant as both of these teaching methods were more likely to be used in a client-based sales course than a non-client-based sales course. In fact, all seven Sales Huddle game adoptions came from courses with client-based projects, while the game was not adopted by any course that did not have a client-based project, and mock sales calls were used in $83 \%$ of client-based courses compared to $40 \%$ of non-client-based courses. Guest speakers were also more likely used by client-based courses as all of the client-based courses used guest speakers, compared to $73 \%$ of non-client-based courses. The client-based courses likely have guest speakers from the client to address issues and training related to the project.

There were more similarities than differences when comparing the teaching methods in sport sales courses to sales courses in business schools. Lecture, guest speakers, role-playing, and sales presentations are a staple of sport sales classes in much the same way they are for professional selling courses in business school settings, as noted in Table 3 . Over $80 \%$ of sport sales courses used these teaching methods. The only two major differences in teaching methods between sales courses in sport and business were in the areas of written sales proposals and the use of videotaping. Sport sales courses utilized written sales proposals at a higher rate than sales courses in business (61\% to $37 \%$ ). One common way for a sport sales course to incorporate a written sales proposal is for students to create a sponsorship proposal. Business school-based courses used videotaping more often than sport-based courses (65\% to $39 \%$ ). Videotaping has a long history of usage and scholarship in professional selling courses, similar to the rich history of client-based experiential projects in sport sales courses.

\section{RESOURCES AND IMPLEMENTATION}

For sales educators considering the adoption of a client-based sales course, it is vital to secure the support of the academic department and the sport organization prior to initiating the project. On the academic side, approval for a sport sales course requires the support of curriculum committees at various levels and the department chair and dean. The fiscal officer also plays an important role to ensure that the university's contracts and grants office processes the contract between the university and sport organization in a timely fashion. Six months of lead time may be needed before a 
contract can be executed, especially if it is the first contract of its kind in the university system. Key elements to the contract include number of sales calls made by the students, how the leads will be generated, and how commission will be handled. Various university regulations can dictate how commissions can be paid, but two primary options include paying directly to students or paying one lump sum to the university for use in a student organization account or scholarship fund. Careful consideration should also be given to who will teach the course. In the event a qualified, full-time faculty member is not available to teach the course, an adjunct faculty member with sales expertise should be identified. However, if the adjunct professor also works for the partnering organization, adequate supervision from the department should ensure that students do not perceive a conflict of interest on the part of the instructor. One potential negative consequence in this scenario is the adjunct faculty member placing too much emphasis on the project to the detriment of other student learning outcomes expected in the course.

Support is also required from the client, particularly the Director of Ticket Sales. In addition to a financial commitment spelled out in the contract, the client need to provide a dedicated project manager responsible for the project. The project manager, typically an account executive with a few years of sales experience, is well positioned to provide leadership and establish a positive sales culture within the class. This person also provides training on the product during at least one class period, answers all student questions during the project, processes all sales forms and completes sales transactions in the client's ticketing system, and makes any necessary changes to the packages and products students are selling. Facility space is also necessary when projects occur at the sports venue. Making sales calls from the client's front office or stadium can enhance the sales culture for the students. The feeling of legitimacy and connection to the team is enhanced when students are in the client's sales environment. Finally, an important detail that needs to be clarified by the client and the university is the exact process by which a sale can be "closed" or processed. Providing students with access to credit card numbers is a significant risk management concern. One way to alleviate this problem is for the client to provide each student with a special URL that serves as a tracking link. This model is commonly used in the independent project model. The student sends the link to the customer by e-mail or text, and the customer completes the order online. If the student completes the form on a paper-based sales order form, it is important for the student to submit the form immediately to the sales supervisor to receive credit for the sale. This model is commonly used in the venuein-venue project model. The most challenging scenario is the on-campus sales center where students are calling warm leads but may not be able to immediately transfer the form to the client because file sharing platforms and e-mail are not appropriate to send the forms to the organization.

Timing is also an important consideration in the establishment of client-based sales projects in sport. Teams and leagues need to be in their selling season when the course is in session, and instructors need enough time to complete the sales training portion of the course with students. For example, selling full season ticket packages 
for a college football team would be difficult for a class in the fall semester that starts in the last week of August. However, selling basketball season tickets in October or November gives the students enough time to complete an adequate sales training. Prime candidates for the fall semester include basketball and hockey. Ideal candidates for the spring semester include baseball and soccer. Football works best for a summer course. Other campus events, spectator events, and participant events can fit any of the semesters depending on the date of the event.

\section{Limitations}

This study has several limitations. First, this study focuses exclusively on students making outbound sales calls. It should be recognized that this is not the only form of sales training that replicates the authentic real world of inside sales. For example, social selling is not included as a sales training method in this study. Other classic sales training methods like videotaping and role-playing are also not included. Second, the response rate was lower than the ideal response rate given the fact there were only 85 members of the population. This decreases the power of the chi-square and t-test results.

\section{CONCLUSION}

Sales courses that engage industry partners to give students real experience selling in the sport industry provide students with a realistic job preview that helps them determine if a career path in sales is a fit moving forward in their career. It is important for students to be educated about the nature of sales careers to avoid pursuing a job that is not a fit. Unfortunately, there is a misconception in sport management education that the best way for students to "get their foot in the door" in sports is through a job in ticket sales (Hamer, 2017; Manteau, 2017; Pierce et al., 2017). This can lead to students pursuing jobs in sales when they should be enhancing their skill set in another area. Sales is a specific career track in the industry, not a catchall for everyone wanting to work in the sport industry. A client-based sales course helps students build a skill set in a field that offers an abundance of entry-level job opportunity and upward mobility, especially for those who are successful in those entry-level positions (Pierce et al., 2017). Sales hiring managers also benefit because candidates with experience during a client-based sales course should be more experienced and committed to sales than candidates who have not completed such an experience in their undergraduate course work. In sum, successful implementation of client-based sales courses provides students with a realistic job preview of a career in sales, prepares those interested in a sales career to succeed upon entry to the industry, provides organizations with a mechanism to identify top sales talent, and in some cases offers more sales training than entry-level salespeople receive from the organization.

The results of this study provide data and recommendations for sales educators and sport management program directors using client-based sales projects. First, many different types of clients partner with sales classes. While the most popular clients 
are in college athletics and professional sports, non-profits, agencies, and participant and spectator events can also provide relevant projects. Second, instructors need to be aware of the pitfalls involved in conducting the independent project model. With nearly half of all client-based sales projects using this model, a risk exists that students will form a negative perception about sales based on a poorly administered class project, which defeats the purpose of exposing students to an authentic sales experience. Third, mock sales calls and the Sales Huddle Game are two teaching methods that differentiate a client-based course from a non-client-based course. Both are rooted in the importance of having students practice sales calls before getting on the phone with a real customer. Mock sales calls require the participation of sales employees from the organization to act as the customer, and the Sales Huddle incorporates roleplaying between students as a fundamental part of its gamified environment. Finally, the results demonstrate that the PSSTM and Pierce and Petersen models have set a framework for the development and implementation of client-based sales projects.

Professional selling courses in business schools can also utilize those two frameworks and the results of this study to provide further refinement to real-world sales projects described by Bussiere (2017) and Rippe (2015). However, in light of the significant investment of time and effort that undergirds the implementation of client-based experiential sales projects, future research should examine the extent to which students completing these projects differ from students who don't complete such an experience with respect to their attitude toward sales, intent to enter the sales profession, and performance upon entering an entry-level sales position. Such research could provide data to support the development of sales courses and projects in more sport management programs, or could provide feedback on how to improve the student experience on future projects to better prepare students for sales positions. Future research could also examine the outcomes of client-based courses in professional selling courses in business schools. 


\section{REFERENCES}

Anderson, R., Dixon, A., Jones, E., Johnston, M., LaForge, R., Marshall, G., \& Tanner, J. Jr. (2005). The scholarship of teaching in sales education. Marketing Education Review, 15(2), 1-10. doi:10.1080/10528008.2005.11488899

Bussiere, D. (2017). Understanding the sales process by selling. Marketing Education Review, 27(2), 86-91. doi:10.1080/10528008.2017.1314188

Chapman, J., \& Avila, R. (1991). Sales training for students: An experiential approach. Marketing Education Review, 1(2), 54-59. doi:10.1080/10528008.1991.11488303

Clapp, B. (2016). 53\% of jobs in the sport industry require this skill. Retrieved from http://www.workinsports.com/blog/53-of-job-in-the-sports-industry-require-this-skill/

Cummins, S., Peltier, J., Erffmeyer, R., \& Whalen, J. (2013). A critical review of the literature for sales educators. Journal of Marketing Education, 35(1), 68-78. doi:10.1177/0273475313481157

Deeter-Schmelz, D., \& Kennedy, K. (2011). A global perspective on the current state of sales education in the college curriculum. Journal of Personal Selling \& Sales Management, 31(1), 55-75. doi:10.2753/PSS0885-3134310104

Fogel, S., Hoffmeister, D., Rocco, R., \& Strunk, D. (2012). Teaching sales. Harvard Business Review, 90(7/8), 94-99.

Hamer, B. (2017). Three reasons you're struggling to get a job in sports. Sports Business. Retrieved from https://sportsbusiness.solutions/3-reasons-youre-strugglingto-get-a-job-in-sports/

Irwin, R., Southall, R., \& Sutton, W. (2007). Pentagon of sport sales training: A 21st century sport sales training model. Sport Management Education Journal, 1(1), 18-39. doi:10.1123/smej.1.1.18

King, B. (2010). Always be closing. SportsBusinessJournal. Retrieved from http:// www.sportsbusinessdaily.com/Journal/Issues/2010/03/20100315/SBJ-In-Depth/ Always-Be-Closing.aspx

Kirby, T. (2017). Ticket markets in sport: Is the secondary market becoming the primary market? In C. K. Harrison \& S. Bukstein (Eds.), Sport business analytics (pp. 35-52). Boca Raton, FL: CRC Press.

Manteau, C. (2017). Sport management professors: Please stop! Retrieved from https:// www.linkedin.com/pulse/sport-mgmt-professors-please-stop-carl-manteau/

McKelvey, S., \& Southall, R. (2008). Teaching sport sponsorship sales through experiential learning. International Journal of Sport Management and Marketing, 4(2/3), 225-242. doi:10.1504/IJSMM.2008.018650

Milner, L. (1995). Telemarketing for the business school as a sales course project. Journal of Marketing Education, 17(3), 73-79. doi:10.1177/027347539501700309 
Mueller, B. (2014). Marketing students at Metro State U. of Denver are graded on ticket sales. The Chronicle of Higher Education, 60(3), 10.

Pierce, D., \& Irwin, R. (2016). Competency assessment for entry-level sport ticket sales professionals. Journal of Applied Sport Management, 8(2), 54-82. doi:10.18666/ JASM-2016-V8-I2-6460

Pierce, D., \& Petersen, J. (2010). Experiential learning in sport sales: Student perceptions of sport sales expectations, skills, and preparation. Sport Management Education Journal, 4(1), 49-59. doi:10.1123/smej.4.1.49

Pierce, D., \& Petersen, J. (2015). Integrating a client-based ticket sales center into a sport sales course. Sport Management Education Journal, 9(1), 66-72. doi:10.1123/ smej.2014-0018

Pierce, D., Petersen, J., \& Meadows, B. (2011). Authentic assessment of experiential learning in sport sales. Sport Marketing Quarterly, 20(2), 75-83.

Pierce, D., Popp, N., \& McEvoy, C. (2017). Selling in the sport industry. Dubuque, IA: Kendall Hunt.

Pierce, D.A. (in press). The state of sport sales education. Sport Management Education Journal.

Popp, N., Simmons, J., \& McEvoy, C. (2017). Sport ticket sales training: Perceived effectiveness and impact on ticket sales results. Sport Marketing Quarterly, 26(2), 99-109.

Rippe, C. (2015). Show and tell: Teaching sales through hands-on selling. Marketing Education Review, 25(1), 15-19. doi:10.1080/10528008.2015.999595

Sheptak, R., \& Menaker, B. (2016). Learning and working with the pros: Student perspectives on an embedded experiential learning project. Journal of Hospitality, Leisure, Sport \& Tourism, 19, 104-114.

Wanless, E., Brewer, R., Johnson, J., \& Judge, L. (2016). Ticket and sponsorship sales: Student perceptions of learning through revenue generation projects. Sport Management Education Journal, 10(2), 115-126. doi:10.1123/smej.2015-0016 